mucus- or chondrin-containing tissues, and in which the cells can progress to puriform structure. To this is added the fact that blood-vessels incorporate themselves into the thickened places, that simultaneously with the thickening there is a hyperaemia of the underlying membranes which can consolidate themselves; it thus becomes clear that one cannot overlook either the irritative nature of the process or the nutritional disturbance. The whole series of events that makes up the well-known inflammatory process is therefore present.

Once the thickening of the inner wall has progressed to a certain degree, fatty metamorphosis usually sets in. But even this does not necessarily always lead to formation of atheroma, and the fatty change itself cannot once and for all be described as atheromatous. The true arterial atheroma arises only from the second kind of patch, namely the real sclerotic (half-cartilaginous) type and in a way often described-namely, not at the surface but under the surface-so that an initially closed and fatty mash-filled focus of softening is formed. In contrast to this it is much commoner in the jelly-like patches to have the fatty softening from within the surface itself in an exactly similar way that the degeneration occurring in joint cartilages in malum senile articulorum leads to superficial destruction. These two processes differ from each other as ulceration differs from abscess formation, except that, instead of pus, a finely granular fatty mass develops and that the process carries with it not a productive but a destructive character. The atheroma, like the abscess, forms enclosed foci which open and likewise show ulcerous surfaces, but these latter retain almost always a greater depth and sharper outline than the primarily superficial festering and fatty suppuration. So little as one calls a superficial ulcer an abscess, so little does the expression atheroma apply to the superficial suppuration of the arteries and for the fatty ulcer.
The atheroma as well as the fatty ulcer begins with a fatty metamorphosis of the connective-tissue particles in the thickened segments of the endothelium-that is, in the same way. Within these particles and in the hard patches apparently in the gaps and cavities of the girder and meshnet, very small fatty particles are deposited, and these gradually accumulate so that eventually one finds thick and large granular cells, often of stellate structure and complete with anastomosing processes. Even here a further difference becomes evident in that in true atheroma the granular cells become larger and more numerous, and eventually, as the ground-substance between them softens, consolidate to one communal form in which the granular spheres quickly change to a granular mash in which larger fat droplets and cholesterol crystals precipitate out. Upon the surface and particularly in the more jelly-like patches in contrast, this formation of the granular cells is often incomplete; the individual cells themselves develop only small amounts of fat and the fat particles therefore lie more scattered within the soft groundsubstance. After destruction of the cells the ground-substance is unable to hold them together in an orderly fashion and then begins, as already described for the ordinary fat-metamorphosis of the intima, at its surface a probably very fine, but not exactly molecular, detachment of the softened products which then lands up in the blood stream. In this way the superficial ulcer is formed and one can detect these macroscopically as being somewhat raw, dull and muddy; microscopically long vertical sections no longer reveal a smooth boundary like on the intima, but one sees liberal prominent fragments, soft girder and fibre tracts, matter protuberances and uneven hollows, indeed everything of minor height and depth. One can see these conditions most easily in the pulmonary artery with prolonged dilatation, while the atheroma formation commonly occurs to a most marked extent in the aorta.

\title{
Chylous Reflux
}

\section{J. B. KINMONTH,* M.S., F.R.c.s. ; G. W. TAYLOR, † M.S., F.R.C.s.}

The term "chylous reflux" is used to describe a backflow of chyle from its normal route from the bowel through the cisterna chyli and the thoracic duct to reach the blood-stream. It may show itself clinically in many different ways. Small blisters containing chyle-chylous vesicles-may appear on the skin in the lower parts of the body and discharge milky fluid, forming one type of chylous fistula. Patients with this condition are often seen in dermatological clinics. Occasionally chylometrorrhoea causes a vaginal discharge of chyle, presenting a diagnostic problem for the gynaecologist. Chyle may collect in the serous cavities of the body-chylothorax, chylous ascites, and chylocele being examples. These are only a few of the ways in which the disordered flow of chyle may show itself. They have been recognized for centuries. Rusznyák et al. (1957) refer to many old case records. The underlying structural and functional defects in the lymphatic system responsible for the clinical effects were largely a matter of conjecture until, in recent years, better methods of studying human lymphatic physiology were developed.

We report here the results of and conclusions from studies of a group of patients with chylous reflux. The lymphatic system has been investigated by lymphangiography, which has given information about the faults causing clinical disturbances. The 19 patients in the group have all been followed long enough after investigation and treatment for conclusions to be drawn about the results and the prognoses. Patients studied more recently have been excluded from review.

^ Department of Surgery, St. Thomas's Hospital Medical School, London. † Surgical Professorial Unit, St. Bartholomew's Hospital, London.
These 19 patients with chylous complications were encountered among 650 patients with primary lymphoedema about whom we have been consulted at St. Thomas's and at St. Bartholomew's Hospitals during 10 years. This shows an incidence of 1 in 34 . No patients with disease of the lymphatic system secondary to usually recognized factors such as neoplasia, trauma, filariasis, or other conditions are included.

The patients, with one exception which is discussed below, fell clearly into two clinical groups of syndromes. In chylous reflux syndrome I there was usually oedema of one lower limb and discharge of chyle from it or from the external genitalia. Lymphangiography showed large incompetent lymphatics, and a patch of capillary angioma was often present on the skin.

In chylous reflux syndrome II the oedema was often congenital and more widespread, affecting several limbs. Lymphangiography revealed few or absent subcutaneous lymph trunks. There was hypoproteinaemia, often with other metabolic disturbance, and the long-term prognosis was poor.

The details of the individual case histories, which are recorded elsewhere (Kinmonth et al., 1964), are not given here, but the main features of the two syndromes are tabulated and analysed. The state of the lymphatic system is discussed in the light of the lymphangiographic findings, and comments are made on treatment and prognosis.

\section{Syndrome I (Megalymphatics)}

Nine patients were male and five female (Table I). There was no marked tendency for one sex to be affected more than 
another. This is in contrast to our figures for primary lymphoedema as a whole where $70 \%$ of the patients were females (Kinmonth et al., 1957), and to Allen's (1934) series, where $87 \%$ were females.

TABLE I.-Syndrome I. Oedema of One Lower Limb, Megalymphatics

\begin{tabular}{|c|c|c|c|c|c|c|c|}
\hline \multirow{2}{*}{$\begin{array}{l}\text { Case } \\
\text { No. }\end{array}$} & \multirow[b]{2}{*}{ Sex } & \multicolumn{2}{|c|}{ Age Onset (years) } & \multicolumn{3}{|c|}{ Site of Reflux } & \multirow[b]{2}{*}{ Skin } \\
\hline & & Oederna & $\begin{array}{l}\text { Chylous } \\
\text { Reflux }\end{array}$ & $\begin{array}{l}\text { Lower } \\
\text { Limb }\end{array}$ & $\begin{array}{l}\text { Ext. } \\
\text { Genit- } \\
\text { alia }\end{array}$ & Other Sites & \\
\hline $\begin{array}{l}1 \\
2 \\
3 \\
4 \\
5 \\
6\end{array}$ & $\begin{array}{l}\mathrm{M} \\
\mathrm{M} \\
\mathrm{F} \\
\mathrm{M} \\
\mathrm{M} \\
\mathrm{F}\end{array}$ & $\begin{array}{r}11 \\
11 \\
10 \\
40 \\
9 \\
14\end{array}$ & $\begin{array}{l}18 \\
14 \\
41 \\
44 \\
13 \\
16\end{array}$ & $\begin{array}{l}+ \\
+ \\
+ \\
+ \\
+ \\
+\end{array}$ & $\begin{array}{l}+ \\
+\end{array}$ & Peritoneum & $\begin{array}{l}+ \\
+ \\
\text { N.R. } \\
+ \\
+\end{array}$ \\
\hline $\begin{array}{r}7 \\
8 \\
9 \\
10\end{array}$ & $\begin{array}{l}M \\
M \\
M \\
M\end{array}$ & $\begin{array}{r}18 \\
9 \\
6 \\
12\end{array}$ & $\begin{array}{r}23 \\
10 \\
7 \\
10\end{array}$ & $\begin{array}{l}+ \\
+ \\
+\end{array}$ & $\begin{array}{l}+ \\
+ \\
+\end{array}$ & $\begin{array}{l}\text { chylometrorrhoea } \\
\text { Chyluria } \\
\text { Chyluria } \\
\text { Tunica vaginalis }\end{array}$ & $\begin{array}{l}+ \\
\text { N.R. } \\
+ \\
+\end{array}$ \\
\hline $\begin{array}{l}11 \\
12 \\
13 \\
14\end{array}$ & $\begin{array}{l}\mathrm{M} \\
\mathrm{F} \\
\mathrm{F} \\
\mathrm{F}\end{array}$ & $\begin{array}{c}\text { N.R. } \\
\frac{1}{3} \cdot 2\end{array}$ & $\begin{array}{c}5 \\
12 \\
1 \cdot 25 \\
3\end{array}$ & $\begin{array}{l}+ \\
+ \\
+\end{array}$ & $\begin{array}{l}+ \\
+\end{array}$ & $\begin{array}{l}\text { Knee-joint chylo- } \\
\text { metrorrhoea }\end{array}$ & $\begin{array}{l}\text { N.R. } \\
+ \\
\text { N.R. }\end{array}$ \\
\hline
\end{tabular}

N.R. $=$ Not recorded

All patients except one developed lymphoedema of one lower limb at an early age and therefore fall into the category of lymphoedema praecox. One patient (Case 4) did not have any oedema until he was 40 years old, and therefore falls into the category of lymphoedema tarda (Kinmonth et al., 1957). In most patients the symptoms or signs of chylous reflux such as the development of vesicles or fistulae appeared within a few years of the onset of oedema.

The area in which the abnormal appearance of chyle manifested itself is analysed in Table I under the heading "site of reflux." In 12 of the 14 cases chyle appeared in one or other lower limb, usually as white vesicles on the thigh or leg. These often broke and discharged milky fluid. In Case 2 the chyle poured out from under the patient's toe-nails, of ten filling his shoe. In seven cases chylous vesicles appeared on the external genitalia. Three cases had chyluria, but in one of these (Case 8) the chyle seemed to enter the urine almost entirely from vesicles in the anterior urethra. Case 6 had a fistula into the bladder. Case 9 had intermittent orthostatic chyluria of slight degree.

Chylometrorrhoea occurred in two patients and responded to operation. This seems to be a rare condition. We know of only one other case, that of Martorell (1963) which was also treated surgically, with a good immediate result.

There was only one instance of chylous ascites in this group (Case 3). This was due to a fistula from a huge pelvic lymphatic allowing chyle to enter the peritoneum, and it was successfully closed at operation. Indeed, in every case and at almost every site at which it appeared in the patients in this group the chyle could be shown to come from a fistulous communication with a very large lymphatic. This is in contrast to the chylous effusions in syndrome II, discussed below, where the effusion appeared as an exudate in a serous cavity without evidence of fistula.

Congenital capillary haemangiomatous patches (" naevi") were present on the skin in 8 out of 10 patients in this group in which records were complete on this particular point. These patches were usually found on the affected limb or trunk. They are recognized (Kinmonth et al., 1957) to be associated with varicose or hyperplastic lymph trunks in patients with primary lymphoedema. Such a naevus was present in only one patient (Case 19) in syndrome II, and that patient was atypical and is discussed below.

\section{Lymphangiography in Syndrome I (Megalymphatics)}

All patients in this group had large incompetent varicose lymphatics of the hyperplastic type often called megalymphatics.
This type of deformity occurs in $14 \%$ of patients with primary lymphoedema, it has been discussed elsewhere and radiographs have been reproduced (Kinmonth, 1960; Kinmonth et al., 1962). The large vessels were seen during surgical operations or were outlined by lymphangiograms. Ten of the 14 patients had radiological lymphangiograms, using water-soluble medium such as a diodone compound or, in more recent cases, oil-soluble medium ("ultra-fluid lipiodol"). The essential physiological fault in this type of chylous reflux is incompetence of the lymph channels in the abdomen, so that chyle which should normally pass from the lacteals to the cisterna chyli and thence upwards through the thoracic duct flows downwards by the retroperitoneal lymphatic pathways to appear in the external genitalia and other abnormal places.

It has always been possible to show the large lymphatics in at least some of their extent, and in certain patients where diodone was used the incompetent pathways could be demonstrated with the dye extending as high as the cisterna chyli. Diodone has, however, some disadvantages. It is absorbed from lymph nodes or vessels in a relatively short time. Also it becomes diluted in the voluminous lymph vessels. It is therefore unsuitable for studying the passage of dye beyond the cisterna into the thoracic duct. Ultra-fluid lipiodol is more suitable for this purpose as it is not absorbed through the walls of the lymph vessels. In three cases (Nos. 1, 9, and 13) some of the dye could be seen in the chest radiographs lying in the thoracic duct. Usually some 3 to $4 \mathrm{~cm}$. of duct contained a column of the dye in its upper portion. The whole duct was never outlined. This finding differs little from the normal. Using the techniques of lymphangiography so far developed, it is most unusual to outline the whole thoracic duct, even where there is every reason to suppose that it is normal, by injections into lymphatics lower down. Dye can usually be seen in it only over a limited extent (Kinmonth and Gough, 1963). Surgical exploration of the terminal portion of the thoracic duct in the neck in one patient (Case 9) revealed no abnormality, and attempts at retrograde catheterization of the duct from the neck or at retrograde injections were unsuccessful, as occurs in the normal thoracic duct (Sharpey-Schafer and Kinmonth, 1957).

We are indebted to Dr. R. Goldrick, of the Rockefeller Institute, New York, for further radiological data about the thoracic duct in Case 13. The image intensifier was used, and with its aid the medium could be seen passing up the duct. A cinematograph film was obtained showing its passage.

We have not therefore been able to find evidence of any organic obstruction in the course of the thoracic duct, but have found some evidence of its patency in the few patients in whom it has been studied.

Since we completed this review, Servelle (1963) has published a paper entitled "Pathology of the Thoracic Duct (17 Case Reports)." He puts forward the hypothesis that "following the obstruction of the thoracic duct " the various clinical manifestations of large lymphatics, chylorrhoea, and so on take place. The evidence advanced for this in the case reports by no means supports the hypothesis, for in most cases there are no observations or data relating to the duct at all. In a few cases lymphangiography of the thoracic duct was attempted by injection of radio-opaque material into lymphatics below it. The radiographs showed only parts of the duct, and did not prove obstruction. He points out that the radio-opaque product becomes rapidly diluted and states: "Moreover, the extra-fluid lipiodol is impossible to use in cases of important dilatations because it forms separate spots. This has been the difficulty, in some cases, in obtaining a good outline of the thoracic duct." In one case necropsy was performed; and here there was evidence of abnormality of the thoracic duct because a large chylous cyst was found in the chest, but the duct itself could not be traced.

It is quite possible that in some cases there may be obstruction of the thoracic duct, but without more data it seems unjustifi- 
able to accept the hypothesis that the duct is obstructed in all cases of chylous reflux with large lymphatics.

\section{Treatment of Chylous Reflux due to Megalymphatics}

Ligation and excision of the incompetent lymphatics above the area of chylorrhoea is the most effective treatment, although one of us (G. W. T.) has achieved some success with cautious injection of sclerosing fluid as an auxiliary method in one patient. Three patients were cured, remaining free from chylous reflux after a single operation. One of them (Case 3) has remained cured for over 10 years. Two were failures, as recurrence took place within six months and further operation was declined. The remaining eight needed several operations; they obtained periods of relief ranging from almost immediate recurrence to over eight years without further chylous troubles. Experience has led us to perform more radical operations at the first attempt at cure, as dissection and excision of the delicate lymph-vessels in the abdomen is easier in the absence of scarring and adhesions.

Interruption of the incompetent pathways is designed to prevent chylous reflux and has little or no effect on oedema, for which appropriate operations or conservative measures may still be needed (Jantet et al., 1961 ; Kinmonth, Rob, and Simeone, 1962).

\section{Chylous Reflux Syndrome II (Lymphatic Deficiency)}

The remaining patients (Cases 15 to 19 , Table II) had different features. The chylous reflux showed itself as an effusion into peritoneum or pleura, there was lymphoedema of several limbs, and lymphangiography revealed deficiency of lymphatic vessels in that they were either absent or hypoplastic. There was hypoproteinaemia.

\begin{tabular}{|c|c|c|c|c|c|}
\hline \multirow{2}{*}{$\begin{array}{l}\text { Case } \\
\text { No. }\end{array}$} & \multirow{2}{*}{ Sex } & \multicolumn{2}{|c|}{ Age of Onset } & \multirow{2}{*}{$\begin{array}{l}\text { No. Limbs } \\
\text { Oedematous }\end{array}$} & \multirow{2}{*}{ Site of Reflux } \\
\hline & & Oedema & Reflux & & \\
\hline $\begin{array}{l}15 \\
16 \\
17\end{array}$ & $\begin{array}{l}M \\
M \\
M\end{array}$ & $\begin{array}{l}6 \\
0 \\
0\end{array}$ & $\begin{array}{l}17 \\
14 \\
0.5\end{array}$ & $\begin{array}{l}2 \\
4 \\
3\end{array}$ & $\begin{array}{l}\text { Peritoneum } \\
\text { Peritoneum } \\
\text { Peritoneum, } \\
\text { pleura }\end{array}$ \\
\hline 18 & M & 0 & 31 & 4 & Peritoneum \\
\hline 19 & $M$ & 2 & 21 & 2 & Pleura \\
\hline
\end{tabular}

All patients in this group were male, the opposite to the normal tendency in primary lymphoedema, but the numbers are too small for much significance to be attached. The oedema of the limbs appeared earlier than in syndrome I, being congenital in three of the patients, and was also different in that two or more limbs were affected.

The chylous complications appeared in all of these patients as effusions into peritoneum or pleura. There were never any vesicles upon the skin, nor external fistulae. In no case could any fistulae be found on exploration of the affected serous cavities, the chylous effusion occurring apparently as a transudate.

The typical lymphangiographic findings in the group were either aplasia or hypoplasia of subcutaneous lymph trunks in the oedematous limbs. Where a trunk was found large enough to be injected it usually tailed off and no dye could be made to show up lymphatics in the abdomen. On surgical exploration of the abdomen no retroperitoneal trunks could be demonstrated with patent blue, but enlarged mesenteric lymphatics could be seen.

It was not possible to demonstrate retroperitoneal lymph pathways or the thoracic duct by methods which would do so in normal subjects. These patients appear, therefore, to have areas of lymphatic aplasia or severe hypoplasia causing damming back of chyle into mesenteric lymphatics, or into the more peripheral thoracic lymphatics, thereby causing transudation of chyle into the serous cavity concerned.

Cases 15 to 18 had serum-protein levels below the normal range, being under 6 in one, under 5 in another, and under 4 g. $/ 100 \mathrm{ml}$. in two more. This is in contrast to syndrome I, where no patient was found to have hypoproteinaemia. This difference may be explained on the grounds that in syndrome II there is an obstruction to the flow of chyle from the mesenteric lymphatics. Our colleague, Dr. B. Creamer, has suggested that this might also cause a loss of protein into the bowel, but we have not yet had an opportunity to prove it. Waldmann et al. (1961) found microscopical evidence of dilatation of intestinal lymphatics in patients with "idiopathic" hypoproteinaemia and protein loss from the bowel. Four of their patients had chylous effusions and three had peripheral oedema of possible lymphatic origin. Those patients did not have their lymphatic systems investigated in the way that ours did, but it is very possible that were this done they would be found to have primary disease of the lymph pathways similar to patients in our syndrome II.

Case 19 does not fall clearly into either group, but inclines more to syndrome II. This patient had a small naevus on the abdominal skin. Lymphangiography showed varicose lowerlimb lymphatics (Kinmonth et al., 1962, Figs. 20.13 and 20.14). However, there was never any chylous reflux into the abdomen or lower limbs. He developed recurrent left-sided chylothorax due to transudation without fistula. It remains cured over six years after pleurodesis.

\section{Prognosis}

The prognosis in syndrome $I$ is good. One patient died from the complications of an associated spinal angioma, but many of the others have been followed for many years and have reached middle or old age. Modern methods of investigation and treatment should make amputations, which used sometimes to be resorted to in the past, unnecessary.

The outlook in syndrome II does not seem so good. One patient (Case 15) died of malignant change (into lymphosarcoma) of bowel lymphatics. A somewhat similar case was reported by Hirschler and Buday (1889). Case 17 (illustrated in Kinmonth et al., 1962, Fig. 20.10) died from severe nutritional changes and intercurrent infection at the age of 9. Case 18 has been severely handicapped by nutritional and metabolic disorders.

\section{Management of Patients with Syndrome II}

Lymphangiographic and other investigations are needed to establish the diagnosis. Laparotomy or thoracotomy may be necessary to search for a fistula that might be closed. One of our patients with recurrent chylothorax was cured by pleurodesis. Medical treatment, such as a high-protein diet and measures to counteract hypocalcaemia, may be helpful.

\section{Summary}

The investigations and clinical courses of 19 patients with primary lymphatic disease who experienced chylous complications have been tabulated and analysed. They were found to fall into two groups or syndromes.

Syndrome 1.-Chylous reflux with megalymphatics. These patients usually had lymphoedema of one lower limb, large incompetent lymphatics, and chylous fistulae. Many of them had congenital naevi on the skin. They were treated by ligation and excision of incompetent megalymphatics. Their general prognosis is good. 
Syndrome II.-Chylous reflux with lymphatic deficiency. These patients had congenital or very early lymphoedema of several limbs, chylous effusions, and hypoproteinaemia. Lymphangiography showed extensive aplasia or hypoplasia of the lymphatic system. The prognosis in this group appears to be worse than in syndrome I.

Detailed case reports are recorded elsewhere and references given.

We are grateful to many colleagues, both physicians and surgeons, too numerous to mention by name, who referred patients for investigation and treatment. Dr. J. E. Dunphy (Dunphy and Foster, 1962, Case 12), Dr. R. Goldrick (Case 13), and Mr. J. H. Williams (Case 14) were kind enough to consult us about patients under their care and later to supply details of the clinical courses of the patients. Many members of our units, and of the radiological departments of our hospitals, helped with the investigation and clinical care of the patients. We wish to thank them for their assistance.
REFERENCES

Allen, E. V. (1934). Arch. intern. Med., 54, 606.

Dunphy, J. E., and Foster, J. H. (1962). Surgical correction of cutaneous chylous reflux into thigh. Film presented at Clin. Congress. Amer. Coll. Surgeons.

Hirschler, A., and Buday, K. (1889). Quoted by Rusznyák, Földi, and Szabo (1957).

Jantet, G. H., Taylor, G. W., and Kinmonth, J. B. (1961). F. cardiovasc. Surg. (Torino), 2, 27

Kinmonth, J. B. (1960). F. roy. Coll. Surg. Edinb., 5, 287. - and Gough, M. H. (1962). Unpublished data. (1963). Unpublished data.

Rob, C. G., and Simeone, F. A. (1962). Vascular Surgery, Arnold, London; Williams and Wilkins, Baltimore, Md., U.S.A.

Taylor, G. W., and Jantet, G. H. (1964). f. cardiovasc. Surg. In press.

Tracy, G. D., and Marsh, J. D. (1957). Brit. F. Surg., 45, 1. artorell, F. (1963). Communication to Int. Cardiovasc. Soc., Rome (to be published in 7 . cardiovasc. Surg.)

Rusznyák, I., Földi, M., and Szabó, G. (1957). Physiologie und Pathologie des Lymphkreislaufes. Akadémiai Kiadó, Budapest.

Servelle, M. (1963). f. cardiovasc. Surg., 4, 702.

Sharpey-Schafer, E. P., and Kinmonth, J. B. (1957). Demonstration to Physiological Society, London.

Waldmann, T. A., Steinfeld, J. L., Dutcher, T. F., Davidson, J. D., and Gordon, R. S. (1961). Gastroenterology, 41, 197.

\title{
Studies of the Inferior Vena Cava in Late Pregnancy
}

\author{
M. G. KERR,* M.B., B.SC., F.R.C.S.ED., M.R.C.O.G. ; D. B. SCOTT, † M.D., F.F.A. \\ ERIC SAMUEL, $\ddagger$ M.D., F.R.C.P.ED., F.R.C.S., F.R.C.S.ED., F.F.R.
}

[With Special Plate]

Brit. med. F., 1964, 1, 532-533

For several years the concept of inferior vena caval occlusion in the supine position in late pregnancy has been current in obstetric teaching. It has been generally thought that severe occlusion occurs in a small minority of cases, giving rise to the well-known supine hypotensive syndrome (Howard, Goodson, and Mengert, 1953). A minor degree of caval obstruction has been believed to occur in at least $50 \%$ of patients (Holmes, 1960).

Recent manometric studies on inferior vena caval pressure in late pregnancy have, however, indicated a rather different state of affairs (Scott and Kerr, 1963). Inferior vena caval pressures were recorded in a number of patients in the supine position in late pregnancy, and each of these records demonstrated two constant features. (1) In the supine position respiratory pressure changes were not transmitted from the thorax to the caudal part of the inferior vena cava ; whereas in the lateral position these cyclical changes were readily detectable at that level. (2) In the supine position the pressure in the inferior vena cava was consistently high (about $20 \mathrm{~cm}$. of water), and this pressure could not be raised by manual occlusion of the inferior vena cava under direct vision, proximal to the level of recording. These findings were interpreted as indicating that in late pregnancy, in the supine position, the inferior vena cava is normally completely occluded and consequently the venous return is ensured by alternative collateral channels.

In an attempt to elucidate this situation it was necessary to supplement these observations on inferior vena caval pressure with an investigation of inferior vena caval flow. This has been achieved by radiological studies of the inferior vena cava in late pregnancy.

* Lecturer in Department of Obstetrics, University of Edinburgh.

+ Consultant Anaesthetist, Royal Infirmary, Edinburgh.

‡ Radiologist-in-Charge, Royal Infirmary, Edinburgh.

\section{Methods}

In an attempt to minimize any foetal hazards from exposure to $x$ rays, our earliest observations were made on four patients known to have an abnormal foetus and in whom pregnancy was to be terminated (two cases of anencephaly; one cervical meningocele; one encephalocele). With these patients three serial films were taken at one-second intervals to follow the venous flow. From our experience with these cases, it was possible to obtain an adequate venogram with one exposure.

In subsequent cases it was felt justifiable to permit a single exposure of a supine film immediately prior to an elective caesarean section performed for various obstetric reasons, as it was considered that the radiation from one single flat film of the abdomen constituted no significant hazard to the mother or to the foetus immediately prior to birth. This procedure was performed on eight patients.

Catheterization of both femoral veins was achieved by percutaneous puncture, using a Seldinger needle 160 and a " polythene" catheter of the same diameter. Simultaneous puncture of both femoral veins was undertaken and both catheters were passed along the femoral vein as far as the junction of the internal and external iliac veins, this site being determined approximately by mensuration. Both catheters were then connected by a Y-piece to a $50-\mathrm{ml}$. syringe. Then $20 \mathrm{ml}$. of $60 \%$ "urografin" was injected by hand pressure and a single film was taken as the injection was completed. In cases where more than one film was possible-that is, those with an abnormal foetus-the first film was taken when $15 \mathrm{ml}$. of dye had been injected, and the second film on completion of the injection. The above procedure was carried out under anaesthesia immediately prior to caesarean section. After the first film had been taken caesarean section was carried out, the catheters being left in situ and isolated from the operation 